\title{
Self-Starvation as Performance
}

HAYLEY RUDKIN

UNIVERSITY OF SYDNEY

Patrick Anderson, So Much Wasted: Hunger, Performance, and the Morbidity of Resistance

Duke University Press, Durham NC, 2010

ISBN 9870822348283 (pb), 9870822348191 (hb)

RRP US\$22.95 (pb), US\$79.95 (hb)

In some respects, seeking to understand the act of self-starvation through the discipline of performance studies seems to be an absurd enterprise. The most meaningful aspects of starvation-the pain of hunger, the weakness of wasted muscle, the death the starving subject will eventually succumb to-are all intensely private, individual experiences, their effect on the starving subject unchanged by the presence of any witnesses. However, that same basic biological process of starvation, the wasting of flesh from a lack of nutrition, also lies at the heart of what it means to be human. Without the consumption of food, we are all inevitably condemned to the promise of a slow and painful death. The very fact of starvation forces us to eat, and in doing so forces us to live through the world around us, not in spite of it. The starvation of another body compels our empathy because it recalls us to the fact that all of humanity is bound to this essential bodily economy. 
Patrick Anderson, associate professor of Communication and a faculty affiliate of Critical Gender Studies and Ethnic Studies at the University of California, San Diego, approaches self-starvation from the field of performance studies. In So Much Wasted: Hunger, Performance, and the Morbidity of Resistance, he relies on the universality of starvation's biological process to underpin this exploration of selfstarvation as performance. Anderson approaches self-starvation as an act which remains in itself essentially constant, but which is performed and understood within a variety of cultural contexts. The essence of self-starvation's immutability lies not merely in the fact that starvation places humanity's bodily economy on display, but that this display is called upon deliberately. The element of intention, relative to this universal process, is central to the means by which the act of self-starvation elicits meaning from those who observe it.

Anderson argues that the observation of a starving body's wasted flesh is fundamentally altered by the knowledge that the subject has deliberately starved themselves. Not only does this knowledge change the observer's comprehension of the starving subject's relationship with the world, it also transforms the observer's understanding of their own position as a witness to this act. While the starvation of the body still demands the empathy of common embodiment, the meaning of this empathic connection is unsettled by the starving subject's perverse wish to destroy the body at the heart of it.

The way in which we comprehend the intention behind the act affects how we feel we should interact with the starving subject. Since we cannot help but recognise that suffering, and eventual death are on display before us, do we have a responsibility as witnesses to intervene? What has caused the subject to starve themselves? For this must to some extent determine whether intervention is called for. Does the body before us signify a deliberate, conscious and rational act? Or does the self-destructive element of self-starvation preclude a rational motive? While starvation elicits empathy, self-starvation both confounds and cries out for understanding.

As Maud Ellmann observes in her own study of self-starvation, The Hunger Artists, there exists a veritable feast of literature, from disciplines as varied as medicine and cultural studies, which seek to answer this call by attributing meaning to the self-starved body. ${ }^{1}$ This vast body of scholarship has very often been 
splintered not only into different disciplinary approaches, but into categories of selfstarvation: anorexia nervosa, hunger strike, performance art, religious fast, selfexperimentation, are merely the most common examples. These acts are all, on a biological level, essentially the same. The difference between anorexia nervosa and a hunger strike lies not in the transformation of the body, but in the way we understand the subject's intention in forcing this transformation. Through this naming of intention, however, we define the act as a whole, deeming the selfstarvation of a hunger strike and that of anorexia nervosa to be qualitatively different.

The categorisation of self-starvation has itself been subject to extensive and lively debate in scholarly literature. Joan Jacobs Brumberg, for example, notes in Fasting Girls that there is evidence the biological process of starvation, regardless of its cause, is potentially addictive. ${ }^{2}$ So at what point does starvation cease to be a deliberate, intentional act and become a bodily function? And if self-starvation is the product of a conscious decision, when does that cognition become pathological? Is anorexia nervosa an illness or a political protest, or both? Is a hunger strike pathological? In answering these questions, we determine whether or not the subject's intention should be approached from the fields of medicine and biology, or the field of cultural studies.

Furthermore, if self-starvation is approached purely from the field of cultural analysis, does it signify an empowering engagement with the subject's cultural context? Is the anorexic body, starving amidst a maelstrom of media images venerating thin bodies and advertising dieting products, marking a victim of this culture or a subversive agent against it? If self-starvation is a deliberate political act, how can it possibly be empowering if it ends with the protester's death? Who has the right to interpret the political significance of self-starvation? In seeking to determine the meaning of a starved body, our own position as witnesses inevitably becomes intertwined with questions of power.

Anderson's decision to read self-starvation in its most basic terms, as a deliberate act which utilises a universal biological principle, allows him to position his analysis outside the power dynamic of categorisation. His objective in So Much Wasted is to investigate how the self-starved body is understood, how it calls into being its witnesses, and how it is defined by those witnesses in turn. In doing so, 
Anderson pulls together a wide variety of case studies from three different categories of self-starvation-anorexia nervosa, performance art and hunger strike-to trace similarities in the ways these acts work as performances.

To draw such disparate examples together into a unified argument, Anderson begins by articulating what he identifies as the most essential elements of self-starvation as an act of performance. What most characterises self-starvation, in Anderson's argument, is that the act of refusing to eat must be repeated over time, and that this repeated refusal constantly and increasingly gestures toward death. The teleology of death is what makes self-starvation compelling to witness, to the extent that the proximity of death correlates directly with the body's significance as a political symbol. Using the work of Freud and Heidegger to, as it were, flesh out this reading, he argues that the act of repeatedly and deliberately propelling oneself toward death should not be read as purely destructive. Citing Peggy Phelan, he argues that this productive living toward death can be usefully understood as a form of performance.

Anderson approaches self-starvation as a performance which takes place within institutions. These state institutions-and by 'state', he refers to 'an assemblage of forces and drives, techniques and tactics' (10)—contain and attribute meaning to self-starvation. Utilising theories of subjectivation, drawn from Althusser, Foucault and Butler, Anderson reads the starving subject's own intention in starving themselves, so crucial to the meaning of self-starvation as an act of performance, through their subjectivation within these amorphous institutions. Not only is the starving body subjectified by those external institutions bearing witness to it, but by the subject themselves. By deliberately causing their starvation, the subject stages a performance of their own subjectivation through repetition while simultaneously refusing it.

The extensive and detailed theoretical discussion, while elegantly written, makes for a somewhat daunting opening to Anderson's argument. However, the need for this solid theoretical grounding becomes increasingly evident as the breadth of Anderson's argument unfolds. He draws on a refreshing variety of case studies, some already familiar to studies of self-starvation, others entirely new. The juxtaposition of figures such as the Brooklyn fasting girl Mollie Fancher and the nineteenth-century nerve doctor Henry S. Tanner, alongside performance artists 
Chris Burden, Ana Mendieta, Marina Abramović and Adrian Piper makes for a fascinating reappraisal of familiar territory. In extending his argument to include performance artists, Anderson does not shy away from also extending his argument beyond the literal and into the metaphorical performance of self-starvation. At this point, the extensive theoretical framing of self-starvation as a form of performance becomes crucial to the continuity of Anderson's argument.

The structure of this argument is deliberately circular, moving from the literal self-starvation of an anorectic patient, to the metaphorical self-starvation of Mendieta's artworks, back to the literal self-starvation of hunger strikes and then to anorexia again. Consequently, while the argument casts itself out to a discussion of Medieta's performance artworks as figurative self-starvation, it is quickly pulled back to the literal starvation of a hunger strike in a Turkish prison. Rather than being arranged as a discussion that winds its way through the bodies of anorexia nervosa, performance art and hunger strike, however, So Much Wasted is primarily arranged as a movement among institutions, from clinic, to gallery, and prison. Consequently, the categories of self-starvation, while not collapsing completely, melt into one another, their distinctions beyond their institutional contexts becoming blurred.

Anderson completes the circularity of his argument by drawing a bridge between anorexia nervosa and hunger strike through the common focus of the feeding tube. The feeding tube's position as an instrument of both nurture and torture has been frequently used to suggest similarities between clinic and prison in the subjectivation of the self-starved body. However, Anderson's discussion of the feeding tube is remarkable in that the morality of the tube's use, while recognised as significant, is not his central concern. Anderson instead reads the feeding tube as marking the point at which the state intervenes between the subject and object of self-starvation. It is a mark of the complexity of Anderson's reading that he is able to draw a connection between the performance of self-starvation within clinic and prison without directly challenging the claims of the institutions which contain these performances. The clinic's claim that it acts in sympathy in order to nurture the anorexic patient, and the prison's claim to punish and restrain its inmates both remain largely intact. Anderson pulls both institutions together by exposing similarities in the mechanism of interaction between state and subject, rather than 
similarities in stated ideology. Framing the feeding tube in this way brings a convincing end to his necessarily broad and amorphous argument: that selfstarvation is a performance which carries a certain degree of legibility across institutions.

This is not to say that Anderson's text is entirely apolitical. He makes clear that the states he examines all operate as controllers of borders, within nationalist projects, capitalist economies and cultures that value consumption. However, Anderson's political argument-that through self-starvation the subject dwells in a place of hunger while the society around them seeks consumption-is certainly not new. The value of So Much Wasted lies in the means by which Anderson arrives at this conclusion. His theoretical approach allows him to investigate the meaning attached to a starving subject's intentions without claiming to define these intentions himself. Anderson instead sees self-starvation as a unique point of intersection in relationships between people, and in this text he maps out the pattern of effects that stem from that point of intersection. The significance of Anderson's work lies it its demonstration of a theoretical approach which will allow future studies of self-starvation to undertake a less overtly politicised reading of the subject, without completely ignoring the importance of the power relationships inherent to the subject itself. For this reason, Patrick Anderson's So Much Wasted is a valuable and illuminating read not just for those working in performance studies, but for anyone approaching the topic of hunger and self-starvation.

Hayley Rudkin is a PhD candidate in the Department of English at the University of Sydney. Her thesis explores representations of hunger in nineteenth-century literature.<hrud5886@uni.sydney.edu.au>

\footnotetext{
-NOTES

1 Maud Ellmann, The Hunger Artists: Starving, Writing and Imprisonment, Virago Press, London, 1993.

2 Joan Jacobs Brumberg, Fasting Girls: The Emergence of Anorexia Nervosa as a Modern Disease, Harvard University Press, Cambridge MA, 1988.
} 